\title{
Energy harvesting from vehicular traffic over speed bumps: A review
}

\begin{abstract}
Energy used by vehicles to slow down in areas of limited speed is wasted. A Traffic Energy Harvesting Device (TEHD) is capable of harvesting vehicle energy when passing over a speed bump. This paper presents a classification of the different technologies used in existing TEHDs. Moreover, an estimation of the energy that could be harvested with the different technologies and their cost has been elaborated. The energy recovered with these devices could be used for marking and lighting of roads in urban areas, making transportation infrastructures more sustainable and environmentally friendly.
\end{abstract}

Keywords: Energy harvesting, speed bump, sustainable roads, traffic speed control.

\section{INTRODUCTION}

A speed control system (SCS) is a device used to slow down vehicles in certain stretches of roads. The first known SCS was placed in New Jersey in 1906 (Clement 1983). The dimensions of these devices are highly variable and can range from 5 to 15 centimeters high or even more. Similarly, the length can vary from a few centimeters to several meters. Systems around one meter or less in length are usually called "Speed Bumps", while those which are longer than a meter are called "Speed Humps" or "Speed Tables" if their upper part is flat. In 1975, the "Transport and Road Research Board" in the United Kingdom determined that the ideal design for these devices corresponds to a parabolic shape of 3.6 meters long and 10 centimeters high (Fig. 1) (Ansari Ardeh et al. 2008).

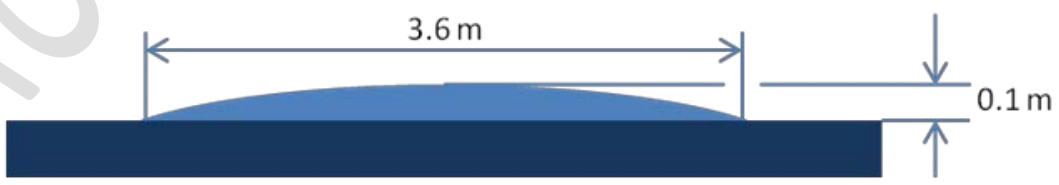

Figure 1: Parabolic hump profile

In the United States, the design guidelines developed by the Institute of Transportation Engineers suggest that the parabolic shape of 3.6 meters in length and 7.5 to 10 centimeters in height should be used as reference (ITE 1997). For the flat topped designs they recommend ramps of 1.83 meters long and 3.05 meters in length for the flat part (Bahar 2007). Other designs have been commonly used, such as the one which was installed for the first time at Seminole County in Florida State (Fig. 2). This design is flat in its upper part with a length of 6.6 meters and a height of 10 centimeters, with curved ramps of 1.8 meters in length (Ewing 1999). 


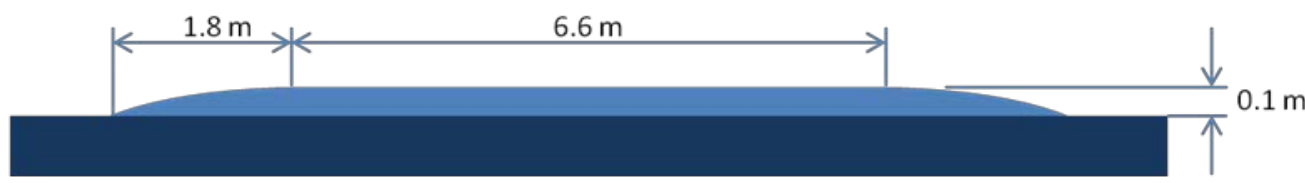

Figure 2: Seminole hump profile

Although the geometry of speed bumps and speed humps has been standardized in many countries, those standards vary greatly from ones to the others. For instance, in Spain this was not standardized until 2008 (Moreno et al. 2011). The Spanish standard distinguishes two sorts of SCSs: Speed Reducers, used to maintain a reduced circulation speed in certain stretches of roads, and Transversal Warning Bands, used to warn drivers of the need for some preventive action, such as reducing speed. There are two different design shapes in the Spanish standards for speed humps: trapezoidally-shaped ones of 4 meters in length in the upper part, ramps between 1 and 2.5 meters long and 10 centimeters in height (Fig. 3); and circularly-shaped of 4 meters in length and 6 centimeters in height (Ministerio de Fomento 2008), these are also named "humpback" due to their shape being very similar to the designs initially established as ideal in the UK and the US.

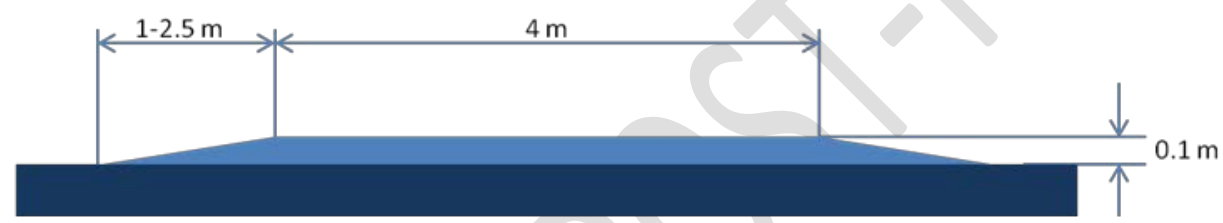

Figure 3: Trapezoidal hump profile

In recent years the use of smaller-sized SCSs has increased. Although SCSs are very effective in reducing vehicle speeds and significantly decreasing the number of crashes, there are some drawbacks, such as the front wheels taking off when the vehicle drives at excessive speed, unpleasant vibrations for passengers at speeds below the limit, failure to transmit strong vibrations when vehicles pass at an inadequate speed, forcing all the drivers to slow down, and inconvenience created to emergency vehicles such as ambulances and fire trucks (Ansari Ardeh et al. 2008; Khorshid et al. 2007).

In order to enhance all these aspects, in recent years several research works have been carried out worldwide to optimize the design of SCSs, relating the different variables involved in the design of these systems: speed, height, length, radius of curvature and vertical acceleration experienced by the vehicle and passengers at the time of contact (Başlamişli \& Ünlüsoy 2009). This has led to the establishment of a general design criteria for SCSs; nevertheless, there are still many different designs and rules depending on country or local authorities (Weber \& Braaksma 2000).

From the point of view of traffic energy harvesting, the SCS typology that suits better with a TEHD is a speed bump. Speed humps are too large for this purpose and the required device would present problems due to its dimensions, weight and complexity.

This document presents the state of the art of the energy harvesting from vehicular traffic over a speed bump. This process should try to take advantage of the vehicles' 
energy when passing over SCSs in the limited speed areas, and use it for lighting and marking of those roads. It should also take into account the comfort and safety standards for the vehicles and passengers, as well as avoiding the increase in the power consumption of the vehicle.

\section{ENERGY HARVESTING TECHNOLOGIES CLASSIFICATION}

A traffic energy harvesting device (TEHD) is capable of transforming the motion and pressure generated by a passing vehicle into useful energy. There are different technologies capable of harvesting energy from vehicles passing over a speed bump. These technologies differ in the way of harvesting energy and its conduction, since all of them use an electromagnetic generator except piezoelectric devices.

The proposed classification of existing devices is based on these different energy harvesting technologies, and how they are used to transform energy from vehicles into useful electric energy. Around one hundred different patents and other intellectual properties have been consulted. There are many similar devices that only differ in some details, accordingly only the most representative have been selected for this classification due to its characteristics, date of publication or importance.

\subsection{HYDRAULIC TEHDS}

An elemental hydraulic TEHD comprises a piston, cylinder, pipes and a hydraulic turbine. They are based on Bernoulli's principle, the compressed fluid inside the piston goes into the external pipes decreasing its pressure but increasing its velocity, due to a cross-section reduction. A hydraulic turbine transforms the fluid speed into mechanical energy and then into electricity (Fig. 4) (Esteban et al. 2006).

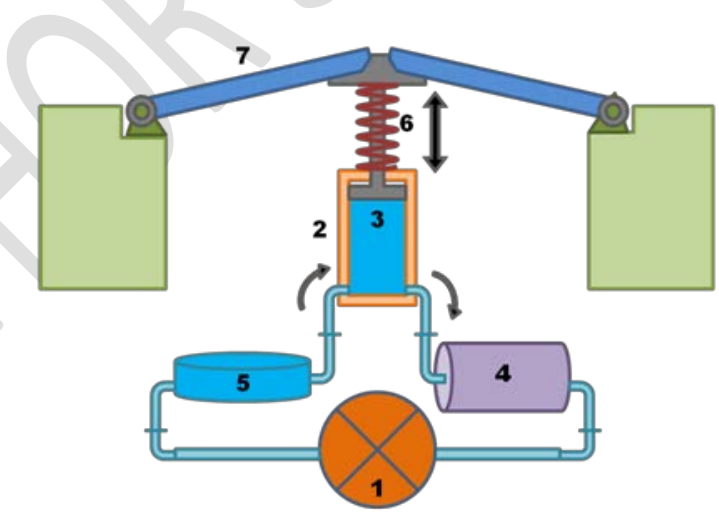

Figure 4: Hydraulic TEHD working scheme. Main components: (1) Hydraulic turbine, (2) Cylinder, (3) Piston, (4) Accumulator, (5) Reservoir, (6) Damper and (7) Ramp.

Table 1: Patents of hydraulic TEHDs

\begin{tabular}{lcc}
\hline Title & Publication number & Author(s) $^{\mathbf{a}}$ \\
\hline Method and apparatus utilizing the weight of moving traffic to & US4339920 (A) & Le Van (1982) \\
produce useful work & AU712078 (B2) & Follman (2000) \\
Road speed limiting device & US6172426 (B1) & Galich (2001)
\end{tabular}


Hydraulic roadbed electricity generating apparatus and method

WO2007013998 (A3)

WO2009037559 (A3)

US7629698 (B2)

US2010198412 (A1)

Adaptive vehicle energy harvesting

Driving an electricity generator using the kinetic, gravitational or air pressure forces present in the flow of vehicular or pedestrian traffic or sea waves

Hydraulic electromagnetic generation device for collecting idle kinetic energy of vehicles

Speed bump capable of electricity generation

Apparatus for generating electric power using hydraulic including speed bump

Water-power flexible speed bump
Adair (2007)

Callegari (2009)

Horianopoulos (2008)

Hendrickson (2010)

Dunn (2010)

Guoqin et al. (2012)

Cho et al. (2012)

Kim Jang et al. (2013)

Ren et al. (2013)

aPatents' references

In the TEHD designed by Le Van (1982), when a vehicle passes over the device, it exerts pressure on a chamber filled with incompressible fluid. This chamber is connected to a circuit with unidirectional control valves to drive the fluid into a motor. Follman (2000) presents two possible configurations, in both cases the passage of the vehicle over the ramp compresses a piston that pushes the fluid from inside the cylinder to a storage system. The cylinder has input and output valves to control the fluid flow during the compression and expansion stage. A generator connected to the storage system provides electricity to the network.

The idea of Galich (2001) is a compressible bed filled with incompressible fluid placed under the road surface. This fluid is pushed by the vehicles weight into a circulation system where fluid energy is transformed into mechanic energy and through a generator into electricity.

Adair (2007) proposes a TEHD with a movable plate that descends over a piston, pushing the incompressible fluid from the cylinder into an electric generator. There are two recovery systems for the piston: in the first, a spring connected to the plate returns the piston to its original position, and in the second, an expansion tank placed between the cylinder and the generator drives the fluid to the cylinder, pushing the piston to its original position. The TEHD designed by Callegari (2009) comprises a pyramidallyshaped movable cover that compresses some oleo dynamic cylinders filled with hydraulic fluid or oil. The fluid is pumped into an oleo dynamic motor connected to a current generator.

Horianopoulos (2008) proposes a system with a low-pressure fluid reservoir, a highpressure fluid accumulator and at least one recovery device placed under the road surface. When traffic passes over, the device pumps the fluid from the reservoir to the accumulator. The high-pressure fluid can be used later to supply an electric generator. The cover shape can be cylindrical or trapezoidal. The system designed by Hendrickson (2010) is made up of four units: in the first, there is a control device to measure the speed and weight of the vehicle; the second unit calculates an acceleration or deceleration range using the speed measured; the third unit compares the measurements and the forth unit adjusts the system reaction as a function of the results from the third unit. These units adjust the resistance offered to the vehicle passage, making the system more efficient. Energy is harvested with a flexible device 
full of fluid. When a vehicle passes over it, the fluid is pushed into a hydraulic motor to generate electricity.

KinergyPower Corporation (2012) presents several devices for energy harvesting from vehicles and pedestrians. The cover of the systems is made up of many small plates. When a vehicle passes over, these compress the pistons placed underneath each plate. At the same time each of these pistons push the fluid into a system where it is stored in accumulators filled with gas and fluid. These accumulators allow the system to store the fluid and supply it to the generator later. The fluid used by the generator is returned to a tank at atmospheric pressure, ready to be used in the pistons again. The dimensions and shape of the system vary with the type of traffic. The KinerBump for light traffic is trapezoidally-shaped, of 8 meters in length and 9 centimeters in height (KinergyPower 2012).

\subsection{PNEUMATIC TEHDS}

The working principle of a pneumatic TEHD is similar to a hydraulic one but with gas or air instead of incompressible fluid. It is obvious that if the gas or air is introduced under atmospheric conditions in the piston, all the compressive force would be used to compress the air and the efficiency of the process would be really low. Hence it is necessary to compress the gas or air beforehand, which implies the need to use a compressor (Fig. 5) (Croser \& Ebel 2000).

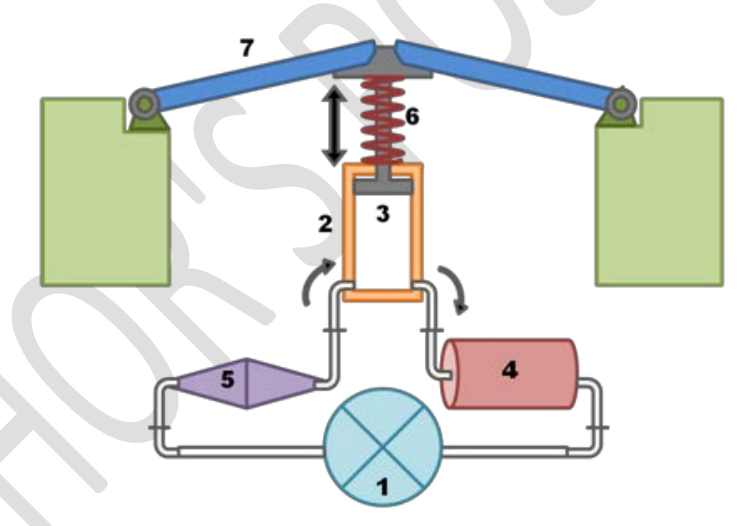

Figure 5: Pneumatic TEHD working scheme. Main components: (1) Generator, (2) Cylinder, (3) Piston, (4) Accumulator, (5) Compressor, (6) Damper and (7) Ramp.

Table 2: Patents of pneumatic TEHDs

\begin{tabular}{lcc}
\hline Title & Publication number & Author(s) $^{\mathbf{a}}$ \\
\hline Apparatus for compressing gas in response to vehicular traffic & US4081224 (A) & Krupp (1978) \\
Vehicle-actuated air compressor and system therefor & US4173431 (A) & Smith (1979) \\
Traffic-operated air-powered generating system & US4212598 (A) & Roche \& Banks (1980) \\
Power generation device of speed reducing plate for vehicle & CN102588234 (A) & Xuchen (2012) \\
Electric generator using speed bump & KR101258233 (B1) & Kim Jae (2012) \\
\hline
\end{tabular}

aPatents' references

Krupp (1978) presents a TEHD with a set of small bumps along a stretch of the road. A chamber filled with gas is placed underneath each bump. The upper wall of the chamber is flexible to facilitate gas compression due to the vehicle weight. All 
chambers are connected in series in order to push the gas from one chamber to the next which is at a higher pressure. The last chambers of the set have a smaller flexible area to increase the pressure exerted by vehicle weight. This highly pressurized air can be used to generate electricity through a turbine. Smith (1979) proposes a TEHD with a small bump in the road surface that compresses a piston when the vehicle passes over it. The device returns to its original position using two springs on the two sides of the cylinder where the air is compressed. The piston comprises input and output valves to allow the entrance of air during the piston elevation and the expulsion in the descent. There is an air pressurized accumulator between cylinders and the generator.

Another TEHD is proposed by Roche \& Banks (1980). The cover is a hinged panel that descends and compresses an air pump. There are two different pumps for this purpose, compressible cylinders placed across the road surface or a piston with a cylinder. Control valves are included to avoid air leaks. An air compressor supplies the air to the cylinders at a suitable pressure, avoiding energy losses in the compression process. The air drives a turbine that provides rotation energy to a generator.

\subsection{MECHANICAL TEHDS}

The basic principle of this sort of harvesters is to transform mechanic force into electricity using a mechanism. There are many different designs; the most commonly used are mainly made up of connection rods, crankshaft and gears to maximize the rotational speed inside the generator (Fig. 6) (Saneifard et al. 2009).

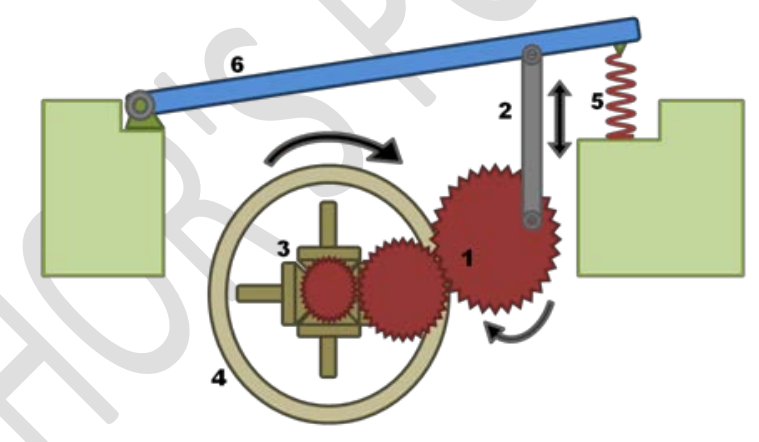

Figure 6: Mechanical TEHD working scheme. Main components: (1) Gears, (2) Connecting rod, (3) Rotor, (4) Stator, (5) Damper and (6) Hinged platform.

Table 3: Patents of mechanical TEHDs

\begin{tabular}{lcc}
\hline Title & Publication number & Author(s) $^{\mathbf{a}}$ \\
\hline Vehicle actuated, roadway electrical generator & US4614875 (A) & McGee (1986) \\
$\begin{array}{l}\text { Energy generation system and method } \\
\text { Road deceleration strip generating set }\end{array}$ & AU2003256053 (A1) & Alperon (2004) \\
$\begin{array}{l}\text { System and method for electrical power generation utilizing } \\
\text { vehicle traffic on roadways }\end{array}$ & CN101285455 (B) & Kun et al. (2008) \\
$\begin{array}{l}\text { Vehicular movement electricity converter embedded within a } \\
\text { road bump }\end{array}$ & WO2008035348 (A3) & Chen (2010) \\
$\begin{array}{l}\text { Highway speed bump energy power generating device } \\
\text { Road way new energy }\end{array}$ & CN201448203 (U) & Kunyi (2010) \\
Generator by rack and pinion gear & KR20100052583 (A) & Hwangbo (2010) \\
& KR20110079798 (A) & Kim Weon (2011)
\end{tabular}


Self-energy generating road speed bump that distinguish is practicable night

Self-generator of speed hump

Vibration generating set and road speed bump with same

Vertically movable electricity generating device for road speed bump
KR20120004062 (U)

KR101345562 (B1)

CN103696918 (A)

CN203584698 (U)
Park (2012)

King Nag (2013)

Wang et al. (2014)

Ma \& Yan (2014)

apatents' references

McGee (1986) proposes a TEHD with a pyramid-shaped cover, which when the vehicle passes over the device, depresses the vertex and activates different gears, transforming the descent of the cover into rotational movement. In the TEHD designed by Alperon (2004) a cylinder partially embedded in the road surface rotates when a vehicle passes over it. This rotation activates a gear system and maximizes the rotation speed in the generator.

Kenney (2009) uses two movable plates assembled with a rocker arm, when the vehicle passes over the first plate it descends and moves the rocker arm. In the same way the second plate returns the rocker arm to its initial position. A generator uses this swinging movement to produce electricity. Another similar TEHD is proposed by Chen (2010). In this device, a semi flexible cover protects the rest of the components. When the vehicle passes over the cover, it depresses a wing and engages a clutch transferring the rotational motion through a flywheel to the rotor of the generator.

Saneifard et al. (2009) presented the experimental results obtained with the device fabricated by their team in the Journal of Engineering Technology. In the device's upper part there is a movable road plate. There is a damping system to return the plate to its original position. When the vehicle passes over the plate, connecting rods transfer this movement to the crankshaft and this to the gears. Finally the rotation reaches the generator, where it is transformed into electrical energy.

Another TEHD is the Electro Kinetic Road Ramp, presented on its website by Highway Energy Systems Ltd (2011). The generation system is comprised of connecting rods, crankshaft, flywheel, gears, generator and a storage system. On the surface there are three assembled road plates that move like a wave when the vehicle passes over them. Tests performed with this ramp were satisfactory and it was placed in some outer London areas in 2009 (Highway Energy Systems 2011).

\subsection{ELECTROMAGNETIC TEHDS}

The electromotive force induced in a circuit is proportional to the variation of the magnetic field flux with time in that circuit. There are two main types of electromagnetic generator, linear and rotational. Most generators used today are based on rotation and are used in numerous applications, from large-scale power generation to small applications for recharging batteries (Harb 2011; Mitcheson et al. 2008). Figure 7 shows a model of a generic electromagnetic TEHD. 


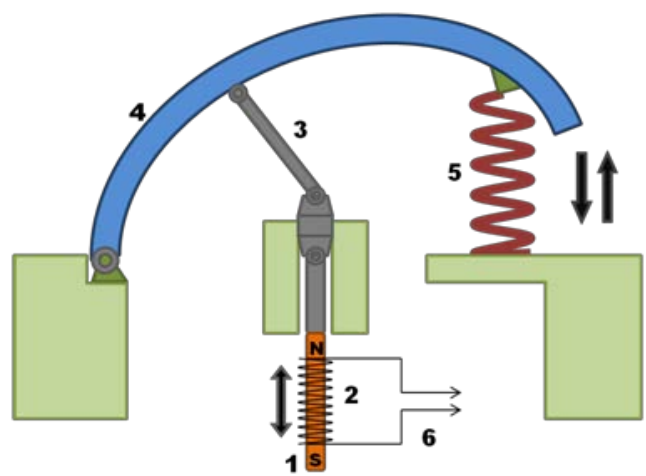

Figure 7: Electromagnetic TEHD working scheme. Main components: (1) Magnet, (2) Coil, (3) Connecting rods, (4) Movable cover, (5) Damper and (6) Circuit.

Table 4: Patents of electromagnetic TEHDs

\begin{tabular}{|c|c|c|}
\hline Title & $\begin{array}{c}\text { Publication } \\
\text { number }\end{array}$ & Author(s) ${ }^{\mathrm{a}}$ \\
\hline Vehicle-actuated road imbedded magneto generator & US7102244 (B2) & Hunter (2006) \\
\hline $\begin{array}{l}\text { Electro-gravity plates for generating electricity from passage of } \\
\text { vehicles over the plates }\end{array}$ & US7589428 (B2) & Ghassemi (2008) \\
\hline $\begin{array}{l}\text { System and method for generating electricity from automobile } \\
\text { traffic }\end{array}$ & US2009173589 (A1) & Nejmeh (2009) \\
\hline $\begin{array}{l}\text { Electric power generating apparatus by using the impact energy } \\
\text { of road bump on the road }\end{array}$ & KR20110017142 (A) & You et al. (2011) \\
\hline Electricity generation and storage device for road speed bump & CN201466944 (U) & Yuansheng et al. (2012) \\
\hline Pavement motive power generation device & CN202250645 (U) & Yunhua \& Daliang (2012) \\
\hline Electric power generating speed bump & US2013193692 (A1) & Dimitriev (2013) \\
\hline $\begin{array}{l}\text { System for converting potential or kinetic energy of a body } \\
\text { weighing upon or travelling over a support or transit plane into } \\
\text { useful energy }\end{array}$ & US8901759 (B2) & Pirisi (2014) \\
\hline
\end{tabular}

The TEHD designed by Hunter (2006) proposes a series of transverse bands embedded in the pavement with magnets inside them. When the vehicle passes over the bands, it depresses the solenoids and induces electric current in them. The device returns to its original position due to a spring placed in the bottom part of the mechanism. Ghassemi (2008) proposes a similar TEHD. When the platform descends, the magnet passes through a solenoid and induces an electric current. On both sides two cushions are adjusted ensuring the rebound and return of the platform to its original position for the next vehicle.

Nejmeh (2009) proposes electricity generation taking advantage of the existing metals inside the vehicles. The TEHD is composed of cylindrical devices with a fixed stator in the inner part where the windings are located, and a movable rotor with magnets in the external part. The external perimeter of the rotor is slightly underneath the road surface. In this way, when vehicles pass over the devices, a magnetic force will appear between the metal components of the vehicles and the magnets of the rotor, generating a movable magnetic field that induces a current in the stator windings.

236 The design of You et al. (2011) has a circular cover in its upper part connected to a spring that absorbs the vehicle weight and returns the cover to its initial position. At the 
same time, the cover is connected to an electromagnetic device by a connecting rod. When the cover descends a magnet moves into a coil and this generates electricity.

Finally, Pirisi (2014) presents a system with an optimization of a tubular permanent magnet linear generator. This optimization is developed using hybrid evolutionary algorithms, reaching the best overall system efficiency and minimizing the impact on the environment and transportation systems.

\subsection{PIEZOELECTRIC TEHDS}

Piezoelectricity is a result of the microscopic properties of certain materials. The phenomenon occurs because when applying mechanical stresses, crystals acquire an electric polarization. This causes a potential difference and the appearance of opposite electrical charges on their surfaces (Khaligh et al. 2010; Cook-Chennault et al. 2008). Lead Zirconate Titanate (PZT) ceramics were discovered in 1954 and since then replaced barium titanate ceramics as the dominating material in all fields of piezoelectric applications. There are two main types of piezoelectric energy harvesting devices: piezoelectric stack transducers (Fig. 8) and piezoelectric bender transducers (Fig.9) (Nuffer \& Bein 2006).

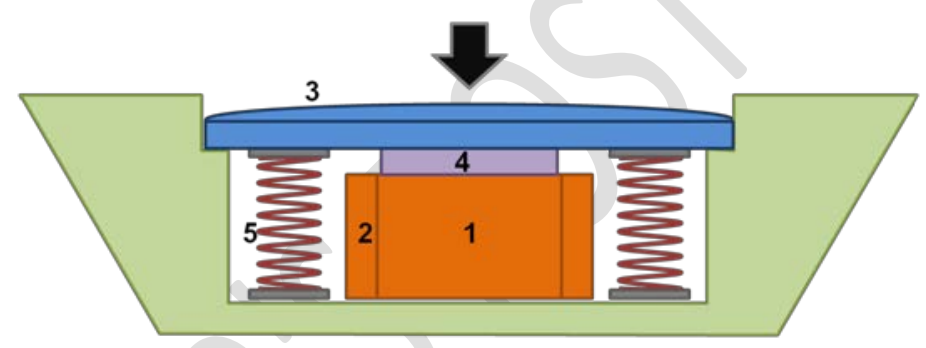

Figure 8: Piezoelectric stack TEHD working scheme. Main components: (1) Piezoelectric plates, (2) Electrodes, (3) Platform, (4) Clamp and (5) Dampers.

Table 5: Patents of piezoelectric TEHDs

\begin{tabular}{lcc}
\hline Title & $\begin{array}{c}\text { Publication } \\
\text { number }\end{array}$ & Author(s) $^{\mathbf{a}}$ \\
\hline $\begin{array}{l}\text { Electro-gravity plates for generating electricity from passage of } \\
\text { vehicles over the plates }\end{array}$ & US7589428 (B2) & Ghassemi (2008) \\
$\begin{array}{l}\text { Speed bump capable of generating power } \\
\text { Multi-layer modular energy harvesting apparatus, system and } \\
\text { method }\end{array}$ & CN202039306 (U) & Hao (2011) \\
$\begin{array}{l}\text { Piezo electromechanical device for recovering energy from } \\
\text { vehicle transit }\end{array}$ & ES2488871 (T3) & Salvini et al. (2014) \\
\hline
\end{tabular}

259 The TEHD proposed by Ghassemi (2008) is made up of several rows of plates 260 containing a piezoelectric material. Above these plates there is a platform and when it 261 descends, an attached clamp compresses the piezoelectric device (Fig. 8), thus obtaining electrical charge. At both sides of the plates two cushions are set ensuring the rebound and return of the platform to its original position for the next vehicle. 


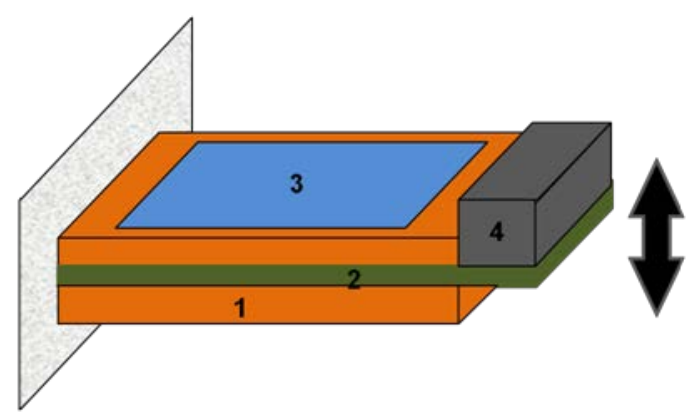

Figure 9: Scheme of a piezoelectric bimorph cantilever beam generator: (1) PZT plates, (2) Shim layer, (3) Electrode and (4) Tip mass.

Messineo et al. (2012) presents a TEHD using a piezoelectric bender device. The prototype consists of an external box embedded in the pavement and an internal box connected by elastic elements. This mechanical configuration allows transferring the vibration produced by the inner box descending to the piezoelectric bender transducer. The flexibility of the system configuration allows modifying the oscillation frequency in order to match the optimal resonance frequency of the PZTs.

Recently, a significant number of piezoelectric energy harvesting applications have been developed to produce electricity from vehicular, train or pedestrian traffic. For instance, the East Japan Railway Company has developed an energy-generating floor to power Tokio subway ticket gates and display systems. It is expected that this system provides $1400 \mathrm{Kw}$ per day for an area of 25 square meters.

Finally, the most known system was developed by the Israeli company Innowattech. In this patent (Abramovich et al. 2010), piezoelectric stack transducers are embedded in the asphalt along the road. The energy used in road deformation is transformed into electric energy through a direct piezoelectric effect. Innowattech (2012) developed and tested this technology and they have collaborated in a project with the Israeli National Road Company (INRC).

\section{CRITICAL REVIEW OF EXISTING TECHNOLOGY}

The aim of this section is to assess the different aspects to take into account when designing a TEHD and make a comparison among the technologies used in these devices.

\subsection{POWER OUTPUT}

The evaluation of the exact amount of energy that could be harvested with the different TEHDs is a complicated task due to the lack of technical data from patents and other existing devices. Assuming that all the TEHDs have the same energy input, it is possible to calculate an approximate value for the electric power output. For this purpose some assumptions and experimental values from other documents are used in addition to the corresponding theory. The results obtained can be used to compare the systems and optimize the selection for each different situation. 
Piezoelectric and electromagnetic technologies are capable of generating more power when they vibrate. Through the adequate mechanism, it is possible to generate a vibration with an optimal frequency, thereby maximizing the power obtained by these TEHDs (Roundy et al. 2003; Cannarella et al. 2011). According to this, the power output values adopted for the piezoelectric and electromagnetic TEHDs will correspond to vibrating systems. The vehicle adopted for all the cases is a standard medium-sized car with a weight of $1800 \mathrm{Kg}$ and the SCS has a height of 8 centimeters.

According to Phalke (2011), for a piezoelectric device of the ceramic PZT 5H type and a vibration frequency of $148.904 \mathrm{~Hz}$, the power obtained is $87.06 \mu \mathrm{W}$.

305

This power is for only one piezoelectric device, but due to its reduced dimensions and depending on the measurements of the SCS, it would be possible to place between 250 and 350 devices. See Table 6.

Zuo et al. (2010) carried out tests with an electromagnetic device similar to what could be placed in a SCS. This system comprises only one coil and supplies average voltages of $10 \mathrm{~V}$ and $2 \mathrm{~W}$ with a frequency of $10 \mathrm{~Hz}$. Similarly to the piezoelectric case, taking into account the dimensions, it would be possible to place between 10 and 20 devices (Table 6).

A hydraulic TEHD with suitable dimensions to be placed in a SCS is described by Arizti (2010). This device with a cylinder of $55 \mathrm{~mm}$ diameter, output holes of $10 \mathrm{~mm}$ diameter and an internal pressure of 350 bars, supplies an average power of around $800 \mathrm{~W}$. A pressure of 350 bars is far higher than what a vehicle could generate in passing over a SCS. Taking the same cylinder and for a vehicle weight of $1800 \mathrm{Kg}$, the pressure inside the cylinder is:

\section{(1) $P=1800 \mathrm{Kg} * 10 \mathrm{~m} / \mathrm{s}^{2} / 0.002375 \mathrm{~m}^{2} \approx 7600000 \mathrm{~Pa}$}

This pressure is nearly a fifth of Aritzi's value (Arizti 2010). It is assumed that the pressure in the cylinder has a direct relationship with the output power (Table 6).

A pneumatic TEHD is not contemplated because its operation is analogous to the hydraulic one but less efficient due to loss in the compression of the gas. Furthermore, a compressor that consumes energy is necessary.

In the mechanical TEHD built by Saneifard et al. (2009), the performance of the device is well described. The shaft of the generator rotates at 3537 revolutions per minute, generates $12 \mathrm{~A}$ of current and a voltage of $12 \mathrm{~V}$. This supplies a power peak of $144 \mathrm{~W}$ per vehicle.

\begin{tabular}{lcl} 
Table 6: Performance of the different TEHDs for the defined boundaries & Notes \\
\hline $\begin{array}{l}\text { TEHD } \\
\text { Technology }\end{array}$ & $\begin{array}{l}\text { Performance } \\
\text { (W per vehicle) }\end{array}$ & \\
\hline Hydraulic & $160-200$ & Calculated from the device of Arizti (2010) assuming linear behaviour. \\
Electromagnetic & $20-40$ & Quoted for Zuo et al. (2010) device at a vibration frequency of $10 \mathrm{~Hz}$. \\
Piezoelectric & $22-30$ & Quoted for a ceramic PZT $5 \mathrm{H}$ at a vibration frequency of $150 \mathrm{~Hz}$.
\end{tabular}


Based on the available data, the defined boundaries and the corresponding theoretical formulas, it is possible to do an appraisement of how the speed bump step height, vehicle weight and speed could affect the power output of the different TEHDs. Because of its configuration and working principles a hydraulic TEHD would be more affected by a variation in the vehicle weight than other devices. In the case of piezoelectric and electromagnetic TEHDs, this depends on whether the variation in the vehicle weight affects the vibration mechanism and hence the vibration frequency. If the speed of the vertical movement does not affect the vibration frequency, the influence of the vehicle weight on the TEHD efficiency would be negligible.

Likewise the height of the SCS is important. Its variation would enhance the performance in all cases, being more important in the hydraulic and electromagnetic TEHDs.

The vehicles' passage at an excessive speed in no case would lead to an improvement, due to the decrease of the pressure over the device. In fact, the front wheels could take off from the road surface, resulting in an incomplete descent of the device and hence a loss of efficiency.

Other important factors to take into account are traffic intensity and heavy vehicles' percentage. These factors would have different effects depending on the TEHD used. For instance, a high percentage of heavy vehicles would produce significantly more power for hydraulic TEHDs but could be negligible for other devices. A SCS could slow down traffic significantly in a residential area with low traffic intensity, whereas in a road with high traffic intensity the device must be easily affordable. A more affordable SCS usually implies less harvested power per vehicle, but more vehicles and vice versa. Hence, it will be very important to study all these factors in order to optimize the most suitable selection in each case. This suggests the possibility of using a mixed system capable of combining different types of technologies: taking advantage both of the potential energy and vertical movement and leading to a more efficient system. For instance, Salvini et al. (2011) proposes a TEHD with electromagnetic and piezoelectric technologies. When a vehicle passes over the device, a magnet goes through a coil and induces a current in it. At the same time, the weight of the vehicle compresses and deforms the piezoelectric material, producing electric voltage.

\subsection{STORAGE}

Vehicular traffic is not a continuous energy source due to its intermittence. Hence it is necessary to use a storage system to take advantage of energy obtained in moments with high traffic intensity and supply it when necessary. The main storage systems are batteries and ultra-capacitors.

Batteries are the most commonly used devices for storing electric energy. Although in the beginning batteries had a low efficiency, in recent years there has been a breakthrough in development of Ion-Lithium and Lithium-Polymer batteries. These 
batteries have a significantly better performance than any other batteries made of other materials with the only drawback of their high cost, although in recent times this is less a problem because of continuous advances in this technology (Burke \& Miller 2011). The new generations of ultra-capacitors fabricated with carbon derivatives can supply more electric power than batteries, and moreover, there is no chemical reaction inside, and hence there is not deterioration with the use cycles (Guan and Liao 2008).

Batteries have a specific energy an order of magnitude higher than ultra-capacitors, and can supply energy during a longer time period (Baisden \& Emadi 2004). On the other hand, ultra-capacitors have a specific power an order of magnitude higher than batteries, and can supply higher power peaks (Nzisabira et al. 2009). As for life span, batteries lose their efficiency with about a few thousand cycles; while ultra-capacitors are able to maintain their performance for more than a million cycles (Guan \& Liao 2008). Ultra capacitors charge and discharge efficiency; that is, the relationship between the energy used to charge it and the energy the device can supply, is about 85 to $98 \%$ depending on the cases, while for batteries it is between 50 and $85 \%$ in the best cases (Table 7). When the current to be supplied is constant and with few power peaks batteries have a good efficiency and life span, reducing the energy demand from the source (Baisden \& Emadi 2004).

Table 7: Comparison between battery and ultra-capacitor capabilities a (Baisden and Emadi, 2004; Burke and Miller 2011)

\begin{tabular}{lccccc}
\hline Storage & $\begin{array}{c}\text { Specific Power } \\
(\mathbf{W} / \mathbf{K g})\end{array}$ & $\begin{array}{c}\text { Specific } \\
\text { Energy } \\
\text { (W-h/Kg) }\end{array}$ & $\begin{array}{c}\text { Supplying } \\
\text { Time (s) }\end{array}$ & $\begin{array}{c}\text { Life Span } \\
\text { (Cycles) }\end{array}$ & $\begin{array}{c}\text { Charge I } \\
\text { Discharge } \\
\text { Efficiency (\%) }\end{array}$ \\
\hline Battery & $<1000$ & $<150$ & $<10000$ & $10^{3}$ & $50-85$ \\
Ultra Capacitor & $<10000$ & $<15$ & $<100$ & $10^{6}$ & $85-98$ \\
\hline
\end{tabular}

${ }^{a}$ These numbers can vary for some devices

The complementary characteristics demonstrated by batteries and ultra-capacitors suggest that they could be combined to create an integrated system. Recent research shows that a system with batteries and ultra-capacitors leads to better performance than a similar system with only one type of device. The combination of batteries and ultra-capacitors results in more compact and lighter systems, with a good relationship between power and energy. Furthermore, this combination allows the reduction of the required battery size, thus obtaining a weight and cost reduction, and a longer life span (Bubna et al. 2012; Burke \& Miller 2011).

\subsection{COST AND FEASIBILITY}

A cost estimation of the different TEHDs has been made assuming some approximate values to obtain an order of magnitude of the actual cost. This cost varies greatly between devices depending on the materials and technology used. In this value, only the cost of the TEHD is included. The installation, cover and other components are not taken into account, being similar for all of them and not as significant as TEHD's cost, except for the size of the elements and installation that usually would be higher for larger devices. 
The piezoelectric device described by Phalke (2011) costs up to $40 €$ in the current 408 market. The number of devices used for calculations in paragraph 4.1 is assumed 409 (Table 8).

410 An electromagnetic linear generator with the suitable characteristics could cost up to $4111000 €$ (Table 8) (Danielsson 2003).

412 A hydraulic turbine model R-125 or CJ-750W with suitable characteristics has a cost of 413 nearly $2000 €$. Also, it is necessary to add the cost of other required components such 414 as cylinders, reservoir, accumulator and valves (Table 8) (3HC Centrales 415 hidroeléctricas 2011).

416 The mechanical device built by Saneifard et al. (2009) costs up to $2000 €$.

Table 8: Estimated payback period for the different TEHDs

\begin{tabular}{lcccc}
\hline TEHD Technology & Hydraulic & Electromagnetic & Piezoelectric & Mechanical \\
\hline Initial Investment $^{\mathrm{a}}(€)$ & 10000 & 15000 & 12000 & 2000 \\
Savings per year $^{\mathrm{b}}(€)$ & 3000 & 1500 & 1800 & 2400 \\
Payback period (years) & 3.3 & 10 & 6.6 & 0.8 \\
\hline
\end{tabular}

${ }^{a}$ These numbers represent the additional value over a standard SCS and depend heavily on the specifications of the different technologies.

${ }^{\mathrm{b}}$ These numbers have been calculated for a traffic intensity of 45000 vehicles per day and a cost of $0.06 € / \mathrm{KWh}$.

421 Results from Table 6 and 8 show that hydraulic and mechanical technologies supply more average power per vehicle and also have an average lower initial investment. This is in agreement with the number of devices studied to elaborate the classification, hydraulic and mechanic TEHDs being the most numerous. Nevertheless, the latest advances in materials like piezoelectric plates have caused an enhancement of their performance and a decrease in their cost. Thus depending on other factors, the placement of other technologies may be more feasible. For instance, hydraulic and mechanical devices are significantly larger than the others and cannot be placed in areas with high traffic intensity due to the height of its step.

\section{FUTURE PROSPECTS}

431 Regarding the different TEHDs reported in the literature, further testing in working 432 conditions is considered necessary, since most of the current devices are presented 433 without any real conditions testing. Moreover, there are very few numerical simulations of TEHDs that allow a more comprehensive study of the design parameters.

There are certain issues that are not covered by the existing TEHDs. Few investigations have taken into account how speed, traffic or vehicle weight affects the performance of a TEHD. A complete study of the combined influence of several design variables is considered necessary. Furthermore, a comparison of initial investment, maintenance cost, operating cost, energy savings and life span of TEHDs versus conventional speed bumps is considered necessary in order to establish the advantages and disadvantages of TEHDs. 
Analyzing the undergoing research in this field and the amount of new devices appearing continuously, the path to follow is on the one hand, the reduction of TEHDs' dimensions in order to make them more affordable reducing installation and maintenance cost, and on the other hand, the combination of different technologies in one device with enhanced materials properties in order to maximize TEHDs' power output.

\section{CONCLUSIONS}

Nowadays there is a strong focus in energy harvesting research, looking for new and clean sources of energy for reducing natural resources consumption and greenhouse gas emissions. Research in energy harvesting from vehicular traffic has an enormous potential to achieve those objectives.

As a summary of all the issues discussed in point 4 the following findings can be drawn:

- Hydraulic and mechanical TEHDs supply more average power per vehicle than piezoelectric and electromagnetic technologies.

- Whereas for a mechanic or hydraulic TEHD, the vehicle weight and step height decisively influence the power output, this is not the case for piezoelectric or electromagnetic devices, where the influence is less significant. In these, the vibration frequency of the device is the most important factor in the final power output.

- Inadequate speeds also influence the efficiency, decreasing the pressure over the TEHD and thus the power output.

- Traffic intensity and percentage of heavy vehicles are other important factors to take into account.

- Mechanical technology has a lower initial investment. Nevertheless, these devices are significantly larger than the others and for this reason cannot be placed in areas with high traffic intensity due to the height of its step. However, a TEHD with a larger initial investment and less power production per vehicle placed in a high traffic intensity area can produce more total power per day, and thus more energy savings and shorter payback periods.

- All this suggests the possibility of using a mixed TEHD capable of combining different technologies resulting in a more efficient system.

- The intermittence of vehicular traffic as an energy source necessitates a storage device. New batteries and ultra-capacitors have excellent storage performances and their combination leads to more compact, lighter systems, with a good relationship between power and energy. Furthermore this combination enables the reduction of the required battery size, thus obtaining a weight and cost reduction, and a longer life span.

Further investigation is needed to analyze the combined influence of design variables, testing in real conditions and a comparison of initial investment, maintenance cost, operating cost, energy savings and life span of TEHDs versus conventional speed bumps. 
3HC Centrales hidroeléctricas. Productos y precios. in CityWeb [database online]. 2011 [cited February 20 2012]. Available from http://www.turbinas3hc.com/turbinas.html.

Abramovich, H., C. Milgrom, E. Harash, L. E. Azulay, and U. Amit. 2010. Multi-layer modular energy harvesting apparatus, system and method. USA filed 2010.

Adair, Sarah. 2007. Hydraulic roadbed electricity generating apparatus and method. Patent WO07013998, filed 2007.

Alperon, Moshe. 2004. Energy generation system. Patent US20040042852, filed 2004.

Ansari Ardeh, H., M. Shariatpanahi, and M. Nikkhah Bahrami. 2008. Multiobjective shape optimization of speed humps. Structural and Multidisciplinary Optimization 37 (2): 20314.

Arizti, Marcos. 2010. Harvesting energy from vehicle suspension. Tampere University of Technology.

Bahar, Geni. 2007. Guidelines for the design and application of speed humps. Institute of Transportation Engineers J ournal (August): 1-71.

Baisden, A. C., and A. Emadi. 2004. ADVISOR-based model of a battery and an ultracapacitor energy source for hybrid electric vehicles. IEEE Transactions on Vehicular Technology 53 (1): 199-205.

Başlamişli, S. C., and Y. S. Ünlüsoy. 2009. Optimization of speed control hump profiles. J ournal of Transportation Engineering 135 (5): 260-9.

Bubna, Piyush, Suresh G. Advani, and Ajay K. Prasad. 2012. Integration of batteries with ultracapacitors for a fuel cell hybrid transit bus. Journal of Power Sources $199(0)(2 / 1)$ : 360-6.

Burke, A., and M. Miller. 2011. The power capability of ultracapacitors and lithium batteries for electric and hybrid vehicle applications. Journal of Power Sources 196 (1): 514-22.

Callegari, Lorenzo. 2009. Vehicular hump for electric energy production. Patent WO2009037559, filed 2009.

Cannarella, J., J. Selvaggi, S. Salon, J. Tichy, and D. -A Borca-Tasciuc. 2011. Coupling factor between the magnetic and mechanical energy domains in electromagnetic power harvesting applications. IEEE Transactions on Magnetics 47 (8): 2076-80.

Chen, Ron. 2010. Vehicular movement electricity converter embedded within a road hump. Patent EP2074326, filed 2010.

Cho, Soo., Uk Joo, Sung., J eung Hwan, Park., Sang Hoon, Lim. 2012. Speed bump capable of electricity generation. Patent KR101256817 (B1), filed 2012.

Clement, J. P. 1983. Speed humps and the thousand oaks experience. Institute of Transportation Engineers J ournal 53 (J anuary): 35-9.

Cook-Chennault, Kimberly Ann, Nithya Thambi, Mary Anne Bitetto, and E. B. Hameyie. 2008. Piezoelectric energy harvesting: A green and clean alternative for sustained power production. Bulletin of Science, Technology \& Society 28 (6): 496-509. 
Croser, P., and F. Ebel. 2000. Air generation and distribution in Pneumatic basics, ed. B. Huber, 130-134. Denkendorf: Festo Didactic Gmbh \& Co.

Danielsson, Oskar. 2003. Design of a linear generator for wave energy plant. Engineering Physics Programme. Uppsala University School of Engineering.

Dimitriev, Victor. 2013. Electric power generating speed bump. Patent US2013193692 (A1), filed 2013.

Dunn, John Martin. 2010. Driving an electricity generator using the kinetic, gravitational or air pressure forces present in the flow of vehicular or pedestrian traffic or sea waves. Patent GB2461860 (A), filed 2010.

Esteban, G., B. Güemez, and A. Peña. 2006. Mecánica de fluidos. Segundo volumen. Departamento de Ingeniería Nuclear y Mecánica de Fluidos ed. Bilbao, Spain: Escuela Técnica Superior de Ingenieros de Bilbao.

Ewing, R. 1999. Traffic calming state of practice. Institute of Transportation Engineers Journal (August): 244.

Follman, A. 2000. Road speed limiting device. Patent US6010277, filed 2000.

Galich, Thomas P. 2001. Electrical energy producing platform and method of use. Patent US6172426, filed 2001.

Ghassemi, Faramarz Frank. 2008. Electro gravity plates for generating electricity from passage of vehicles over the plates Patent WO08127823, filed 2008.

Guan, M. J., and W. H. Liao. 2008. Characteristics of energy storage devices in piezoelectric energy harvesting systems. Journal of Intelligent Material Systems and Structures 19 (6): 671-80.

Guogin, Yu., Jun, Liu., Bao, Hailong., Liu, Junbiao., Duan, Zhongxia., Huo, Rongling. 2012. Hydraulic electromagnetic generation device for collecting idle kinetic energy of vehicles. Patent CN102536691 (B), filed 2012.

Hao, Jin. 2014. Speed bump capable of generating power. Patent CN202039306 (U), filed 2014.

Harb, A. 2011. Energy harvesting: State-of-the-art. Renewable Energy 36 (10): 2641-54.

Hendrickson, Brian S. 2010. Adaptive vehicle energy harvesting Patent W010063012, filed 2010.

Highway Energy Systems. Electro kinetic road ramp. In Sharpe Web Design [database online]. 2011 [cited December 20 2011]. Available from http://www.hughesresearch.co.uk/.

Horianopoulos, Dimitrios, and Stefanos Horianopoulos. 2008. Traffic-actuated electrical generator apparatus Patent EP1945948, filed 2008.

Hunter, J ohn P. 2006. Vehicle actuated road imbedded magneto generator. Patent US7102244, filed 2006.

Hwangbo, Sun. 2010. Road way new energy. Patent KR20100052583 (A), filed 2010.

Innowattech Ltd. Innowattech piezo electric generator (IPEG). in e-way [database online]. 2012 [cited March 29 2012]. Available from http://www.innowattech.co.il/. 
ITE. 1997. Traffic engineering council speed humps task force. Guidelines for the design and application for speed humps. Institute of Transportation Engineers.

Kenney, Terry Douglas. 2009. System and method for electrical power generation utilizing vehicle traffic on roadways. Patent US7530761, filed 2009.

Khaligh, A., P. Zeng, and C. Zheng. 2010. Kinetic energy harvesting using piezoelectric and electromagnetic technologies: state of the art. IEEE Transactions on Industrial Electronics 57 (3): 850-60.

Khorshid, E., F. Alkalby, and H. Kamal. 2007. Measurement of whole-body vibration exposure from speed control humps. Journal of Sound and Vibration 304 (3-5): 640-59.

Kim Jae, Heung, 2012. Electric generator using speed bump. Patent KR101258233 (B1), filed 2012.

Kim Jang, Mok., Hyun Keun, Ku., Dong Youn, Kim., Jae Heung, Kim., J un Ho, Lee. 2013. Apparatus for generating electric power using hydraulic including speed bump. Patent KR101236343 (B1), filed 2013.

Kim Weon, Ho. 2011. Generator by rack and pinion gear. Patent KR20110079798 (A), filled 2011.

KinergyPower. KinerBumps. in Hudson Fusion [database online]. 2012 [cited J anuary 18 2012]. Available from http://www.kinergypower.com/index.shtml.

King Nag, J in. 2013. Self-generator of speed hump. Patent KR101345562 (B1), filed 2013.

Krupp, Walter H. 1978. Apparatus for compressing gas in response to vehicular traffic. Patent US4081224, filed 1978.

Kun, Jiang., Cai, Xiaojing., Zhang, Kewen., Zhang, Shuibo. 2008. Road deceleration strip generation set. Patent CN101285455 (B), filed 2008.

Kunyi, Tang. 2010. Highway speed bump energy power generating device. Patent CN201448203 (U), filed 2010.

Le Van, Wayne P. 1982. Method and apparatus utilizing the weight of moving traffic to produce useful work. Patent US4339920, filed 1982.

Ma, Tianfu., Yan, Yizhi. 2014. Vertically movable electricity generating device for road speed bump. Patent CN203584698 (U), filed 2014.

McGee, Terrill A. 1986. Vehicle actuated, roadway electrical generator. Patent US4614875, filed 1986.

Messineo, A., A. Alaimo, M. Denaro, and D. Ticali. 2012. Piezoelectric bender transducers for energy harvesting applications. Paper presented at Energy Procedia.

Ministerio de Fomento. Instrucción Técnica Para La Instalación De Reductores De Velocidad y Bandas Transversales De Alerta En Carreteras De La Red De Carreteras Del Estado, (2008).

Mitcheson, P. D., E. M. Yeatman, G. K. Rao, A. S. Holmes, and T. C. Green. 2008. Energy harvesting from human and machine motion for wireless electronic devices. Proceedings of the IEEE 96 (9): 1457-86. 
Moreno, A., García, A., and Romero, M. 2011. Speed table evaluation and speed modeling for low-volume crosstown roads.

Nejmeh, Mark J. 2009. System and method for generating electricity from automobile traffic Patent WO09089336, filed 2009.

Nuffer, J., and T. Bein. 2006. Applications of piezoelectric materials in transportation industry. Paper presented at Proc. of the Global Symposium on Innovative Solutions for the Advancement of the Transport Industry (TRANSFAC).

Nzisabira, J., Y. Louvigny, and P. Duysinx. 2009. Comparison of ultra capacitors, hydraulic accumulators and batteries technologies to optimize hybrid vehicle ecoefficiency. Paper presented at POWERENG 2009 - 2nd International Conference on Power Engineering, Energy and Electrical Drives Proceedings.

Park, Jeung. 2012. Self-energy generating road speed bump that distinguishes is practicable night. Patent KR20120004062 (U), filed 2012.

Phalke, Rohit. 2011. Comparison of mechanical and piezoelectric power extraction from a speed bump device. San Diego State University.

Pirisi, Andrea. 2014. System for converting potential or kinetic energy of a body weighing upon or travelling over a support or transit plane into useful energy. Patent US8901759 (B2), filled 2014.

Ren, HongJ uan., Xu, Biao., Zhang, Ruoping., Du, Guanfeng. 2013. Water-power flexible speed bump. Patent CN203229881 (U), filed 2013.

Roche, Dwain F., and Stanley E. Banks. 1980. Traffic-operated air-powered generating system. Patent US4212598, filed 1980.

Roundy, S., P. K. Wright, and J. Rabaey. 2003. A study of low level vibrations as a power source for wireless sensor nodes. Computer Communications 26 (11): 1131-44.

Salvini, Alessandro, Francesco Riganti Fulginei, and Daniele Altomonte. 2011. Piezo electromechanical device for recovering energy from vehicle transit. Patent WO2011141812, filed 2011.

Saneifard, R., R. Dana, and A. Sianati. 2009. Design and implementation of an electromechanical system utilizing speed bumps to generate electric power. Journal of Engineering Technology 26 (2): 16-23.

Smith, Roland L. 1979. Water vehicle-actuated air compressor and system therefor. Patent US4160624, filed 1979.

Wang, Zhihua., Wang, Li., Wang, Bowen. 2014. Vibration generating set and road speed bump with same. Patent CN103696918 (A), filed 2014.

Weber, P. A., and J. P. Braaksma. 2000. Towards a north American geometric design standard for speed humps. ITE Journal (I nstitute of Transportation Engineers) 70 (1): 30-4.

Xuchen, Gao. 2012. Power generation device of speed reducing plate for vehicle. Patent CN102588234 (A), filed 2012.

You, Young J un, Ki Tae Park, and Su Tae Kang. 2011. Electric power generating apparatus by using the impact energy of road bump on the road. Patent KR20110017142, filed 2011. 
Yuansheng, Li., Wang, Xudong., Xu, Xiaozhuo., Xue, Mengjiao., Yuan, Hang., Zhang, Zhiyuan. 2012. Electricity generation and storage device for road speed bump. Patent CN201466944 (U), filed 2012.

Yunhua, Jiang., Daliang, Shi. 2012. Pavement motive power generation device. Patent CN202250645 (U), filed 2012.

Zuo, L., B. Scully, J. Shestani, and Y. Zhou. 2010. Design and characterization of an electromagnetic energy harvester for vehicle suspensions. Smart Materials and Structures 19 (4). 